\title{
Editorial \\ Articular cartilage stem cell signalling
}

\section{Camilla Karlsson and Anders Lindahl}

\begin{abstract}
Department of Clinical Chemistry and Transfusion Medicine, The Sahlgrenska Academy at Gothenburg University, PO Box 400, SE405 30 , Gothenburg, Sweden
\end{abstract}

Corresponding author: Anders Lindahl, anders.lindahl@clinchem.gu.se

Published: 24 July 2009

This article is online at http://arthritis-research.com/content/11/4/121

Arthritis Research \& Therapy 2009, 11:121 (doi:10.1186/ar2753)

(c) 2009 BioMed Central Ltd

See related research by Grogan et al., http://arthritis-research.com/content/11/3/R85

\begin{abstract}
The view of articular cartilage as a non-regeneration organ has been challenged in recent years. The articular cartilage consists of distinct zones with different cellular and molecular phenotypes, and the superficial zone has been hypothesized to harbour stem cells. Furthermore, the articular cartilage demonstrates a distinct pattern regarding stem cell markers (that is, Notch-1, Stro-1, and vascular cell adhesion molecule-1). These results, in combination with the positive identification of side population cells in articular cartilage, give additional support for the hypothesis that articular cartilage has residing stem cells with a potential regenerative capacity where the controlling mechanism could be future biomarkers or drug targets or both.
\end{abstract}

Articular cartilage has been considered a post-mitotic tissue with virtually no cellular turnover. This has been based on the fact that the tissue is hypocellular and avascular and relies on diffusion for its nutrient supply. In the previous issue of Arthritis Research \& Therapy, Grogan and colleagues [1] addressed the question of the localization of progenitor cells in healthy and osteoarthritic (OA) cartilage using Notch-1, Stro-1, and vascular cell adhesion molecule-1 (VCAM-1) as markers for stem cells.

Articular cartilage has been proposed to consist of only terminally differentiated cells in adults, lacking progenitor cells - a dogma well-established in the textbooks. However, this dogma has been challenged in recent years [2-4] by the hypothesis that a progenitor cell population resides in the superficial zone of the cartilage. An additional challenge to the dogma is the fact that articular cartilage is not homogenous; instead, biochemical and morphological variations are seen from the surface zone (SZ) through the middle zone $(M Z)$ and down to the deep zone (DZ). In the SZ, cells are flattened and secrete lubricin [5]; in the $M Z$, the cells are rounded and arranged in columnar structure and produce cartilage intermediate layer protein (CILP) [6]; but in the DZ, the cells are considerably larger and express type $\mathrm{X}$ collagen and alkaline phosphatase.

Grogan and colleagues [1] related their finding to the three different zones in hyaline cartilage. The authors demonstrated similar staining patterns for the three makers but with a distinct zonal distribution pattern in healthy cartilage. The highest frequencies of stained cells were found in the SZ.

The presence of progenitor cells is a key component to rapid and successful regeneration of a variety of tissues. The few studies performed concerning the regenerative potential of embryonic cartilage are somewhat conflicting. Namba and colleagues [7] reported that laceration of foetal cartilage has an intrinsic reparative capacity. On the other hand, McCullagh and colleagues [8] found no evidence of healing when transecting the cartilaginous radii of stage 32 embryos in ovo. For future treatments of cartilage injuries, it is of interest to ask whether cartilage has the ability to self-repair and whether this ability is dependent on the presence of immature progenitor cells.

Studies regarding cartilage development have also shed light on the question of whether progenitor cells are present in articular cartilage. There is increasing evidence that articular cartilage growth during development is achieved by apposition from the articular surface until puberty [4]. A population of progenitor cells must then reside within the $S Z$ to provide transient amplifying progenies for such a mechanism to occur. Through the use of BrdU (bromo-deoxyuridine) injections, it has been demonstrated that there are slow-cycling cells, a trait characteristic of progenitor cells, in the SZ of articular cartilage [4]. The proposed articular cartilage progenitors have also been isolated [2]. These cells express the proposed progenitor marker Notch-1 and possess a high colony-forming efficiency that was abolished when Notch signalling was blocked [2].

$\mathrm{DZ}=$ deep zone; $\mathrm{MZ}=$ middle zone; $\mathrm{OA}=$ osteoarthritic; $\mathrm{SZ}=$ surface zone; $\mathrm{VCAM}-1$ = vascular cell adhesion molecule-1. 
The surprisingly high numbers of cells positive for stem cell markers in the paper by Grogan and colleagues [1] could not possibly correlate to the number of progenitor cells or stem cells in articular cartilage. To determine stem cell identity, the authors used a second approach to detect the so-called side population cells defined by Hoechst dye 33342 which identifies stem cells by their ability to excrete the dye by the multi-drug transporter ABCG2. The authors were also able to demonstrate that the side population had increased chondrogenic potential compared with non-side population cells.

In OA cartilage, the staining pattern of stem cell markers differed from that of healthy cartilage, with increased Notch staining in the $M Z$ as well as increased VCAM-1 staining in the $M Z$ and $D Z$. These results are in line with other recent findings [9]. These markers also differed in staining frequency within OA clusters, indicating an altered signalling through pathways important for stem cells. However, no differences in side population cells were found between healthy and OA cartilage.

The paper by Grogan and colleagues [1] gives a new piece of evidence of the regenerative potential of articular cartilage. Human articular chondrocytes are multipotent with a differentiation pattern similar to that of mesenchymal stem cells $[10,11]$. Furthermore, the appositional growth of cartilage as suggested by Dowthwaite and colleagues [2] indicates a functional role for the superficial layer of cartilage. The increased activation of Notch-1, Stro-1, VCAM-1, and Sox-9 in $O A$ cartilage could indicate signalling from a regenerative response in cartilage, and elucidating the signalling pathway could have bearing on the development of new diagnostic markers for diseased cartilage and the identification of potential new drug targets in the future. Additional research is required in order to determine (a) the location and (b) the function of the stem cells in human articular cartilage. Furthermore, the reason for a high number of cells expressing progenitor markers in articular cartilage needs to be elucidated. Either the signalling pathways are involved in metabolic processes unrelated to regenerative processes or in progenitor cell signalling. The latter, as the authors state, could be due to the fact that no 'rescue team' of circulating stem cells will home to and repair the damaged cartilage as is the case in vascularized wound areas and therefore the number of progenitor cells has to be higher in articular cartilage compared with other tissues.

\section{Competing interests}

The authors declare that they have no competing interests.

\section{References}

1. Grogan SP, Miyaki S, Asahara H, D'Lima DD, Lotz MK: Mesenchymal progenitor cell markers in human articular cartilage: normal distribution and changes in osteoarthritis. Arthritis Res Ther 2009, 11:R85.

2. Dowthwaite GP, Bishop JC, Redman SN, Khan IM, Rooney P, Evans DJ, Haughton L, Bayram Z, Boyer S, Thomson B, Wolfe MS, Archer CW: The surface of articular cartilage contains a progenitor cell population. J Cell Sci 2004, 117(Pt 6):889-897.
3. Hattori S, Oxford C, Reddi AH: Identification of superficial zone articular chondrocyte stem/progenitor cells. Biochem Biophys Res Commun 2007, 358:99-103.

4. Hayes AJ, MacPherson S, Morrison H, Dowthwaite G, Archer CW: The development of articular cartilage: evidence for an appositional growth mechanism. Anat Embryol (Berl) 2001, 203:469-479.

5. Schumacher BL, Block JA, Schmid TM, Aydelotte MB, Kuettner $\mathrm{KE}$ : A novel proteoglycan synthesized and secreted by chondrocytes of the superficial zone of articular cartilage. Arch Biochem Biophys 1994, 311:144-152.

6. Lorenzo P, Bayliss MT, Heinegard D: A novel cartilage protein (CILP) present in the mid-zone of human articular cartilage increases with age. J Biol Chem 1998, 273:23463-23468.

7. Namba RS, Meuli M, Sullivan KM, Le AX, Adzick NS: Spontaneous repair of superficial defects in articular cartilage in a fetal lamb model. J Bone Joint Surg Am 1998, 80:4-10.

8. McCullagh JJ, Gill P, Wilson DJ: Repair of cartilaginous fractures during chick limb development. J Orthop Res 1990, 8: 127-131.

9. Karlsson C, Brantsing C, Egell S, Lindahl A: Notch1, Jagged1, and HES5 are abundantly expressed in osteoarthritis. Cells Tissues Organs 2008, 188:287-298.

10. Barbero A, Ploegert S, Heberer M, Martin I: Plasticity of clonal populations of dedifferentiated adult human articular chondrocytes. Arthritis Rheum 2003, 48:1315-1325.

11. Tallheden T, Dennis JE, Lennon DP, Sjögren-Jansson E, Caplan Al, Lindahl A: Phenotypic plasticity of human articular chondrocytes. J Bone Joint Surg Am 2003, 85-A Suppl 2:93-100. 